\title{
Kinerja Motor Induksi Tiga Phasa Sebagai Pompa Air Gedung Bertingkat Di Kantor Walikota Pekanbaru Riau
}

\author{
M Bagus Aditya ${ }^{1}$, Atmam $^{2}$, Elvira Zondra ${ }^{3}$ \\ 1,2,3 Program Studi Teknik Elektro, Fakultas Teknik, Universitas Lancang Kuning \\ Jl. Yos Sudarso km. 8 Rumbai, Pekanbaru, Telp. (0761) 52324 \\ E-mail : bagusaditya197@gmail.com, atmam@unilak.ac.id, elviraz@unilak.ac.id
}

\begin{abstract}
Abstrak
Motor listrik merupakan mesin listrik yang merubah energi listrik menjadi energi gerak. Pemanfaatan energi gerak ini yang kemudian banyak digunakan oleh beberapa gedung bertingkat untuk mempermudah proses pendistribusian air. Kantor Walikota Pekanbaru memiliki motor listrik untuk pendistribusian air yang memiliki kapasitas daya $7,5 \mathrm{~kW}$ sebagai mesin penggerak pompa. Penelitian ini dilakukan pada motor induksi tiga phasa di kantor Walikota Pekanbaru untuk mengetahui kinerja motor terhadap perubahan bukaan valve. Saat bukaan valve minimal diperoleh arus stator 6,215 Amper, arus rotor 4,180 Amper, putaran rotor 2979 rpm, torka induksi 8,044 N.m dan torka beban 7,987 N.m. Saat bukaan valve medium diperoleh arus stator 8,389 Amper, arus rotor 7,236 Amper, putaran rotor $2963 \mathrm{rpm}$, torka induksi 14,257 N.m dan torka beban 14,080 N.m. Saat bukaan valve maksimal diperoleh arus stator 10,006 Amper, arus rotor 9,319 Amper, putaran rotor $2950 \mathrm{rpm}$, torka induksi 18,080 N.m dan torka beban 17,798 N.m.
\end{abstract}

Kata Kunci : Motor Induksi, Arus Stator, Arus Rotor, Torka, Putaran.

\begin{abstract}
Electric motors are electric machine that convert electrical energy into motion energy. Utilization of this motion energy is subsequently widely used by several high-rise buildings to facilitate the process of water distribution. Pekanbaru city Mayor Office has an electric motor for water distribution that has a power capacity of $7.5 \mathrm{~kW}$ as the engine driving the pump. Research is done on a three-phase induction motor at Pekanbaru city Mayor Office to find out the motor performance for the changing of valve openings. When a minimum valve opening is obtained, the stator current reaches 6,215 Amperes, the rotor current reaches 4,180 Amperes, the rotor rotation reaches 2979 rpm, the rotor torque is $8,044 \mathrm{N.m}$ and the load torque is 7,987 N.m. When the opening of the medium valve is obtained, the stator current reaches 8,389 Amperes, the rotor current reaches 7,236 Amperes, the rotor rotation reaches $2963 \mathrm{rpm}$, the rotor torque is $14,257 \mathrm{~N} . \mathrm{m}$ and the load torque is $14,080 \mathrm{N.m}$. When the maximum valve opening is obtained, the stator current reaches 10,006 Amperes, the rotor current reaches 9,319 Amperes, the rotor rotation reaches $2950 \mathrm{rpm}$, the rotor torque is 18,080 N.m and the load torque 17,798 N.m.
\end{abstract}

Keywords: Induction motor, Stator Current, Rotor Current, Torque, Rotation

\section{PENDAHULUAN}

Kota Pekanbaru adalah Ibukota dan kota terbesar di provinsi Riau. Kota ini merupakan salah satu sentra ekonomi terbesar di Pulau Sumatra, dan termasuk sebagai kota dengan tingkat pertumbuhan, migrasi dan urbanisasi yang tinggi. Kota ini berawal dari sebuah pasar (pekan) yang didirikan oleh para pedagang Minangkabau di tepi Sungai Siak pada abad ke18. Hari jadi kota ini ditetapkan pada tanggal 23 Juni 1784. Kantor Walikota Pekanbaru sekarang berada di jl. Badak Kecamatan Tenayan Raya, kantor Walikota ini baru beroprasi 25 Maret 
SainETIn (Jurnal Sain, Energi, Teknologi \& Industri), Vol. 4 No. 2, Juni 2020, pp. 57 - 64

ISSN 2548-6888 print, ISSN 2548-9445 online

2019 yang memiliki gedung 8 lantai, untuk memenuhi kebutuhan air bersih di gedung bertingkat 8 ini pihak dari kantor Walikota memanfaatkan motor listrik untuk memenuhi ketersediaan air bersih yang memadai.

Motor listrik merupakan mesin listrik yang merubah energi listrik menjadi energi gerak. Pemanfaatan energi gerak ini yang kemudian banyak digunakan oleh beberapa gedung bertingkat untuk mempermudah proses pendistribusian air. Kantor Walikota Pekanbaru memiliki motor listrik induksi yang memiliki kapasitas daya 7,5 kW (10 HP) sebagai mesin penggerak pompa. Setiap motor memiliki kinerja yang berbeda. Motor induksi yang baik adalah yang memiliki nilai efisiensi lebih dari $80 \%$. Untuk mengetahui kinerja motor induksi yang di gunakan pada motor induksi tiga phasa sebagai penggerak pompa di kantor Walikota Pekanbaru dilakukan penelitian mengenai efisiensi motor induksi.

Dampak yang ditimbulkan akibat belum pernah dilakukan analisa terhadap kinerja motor induksi tersebut adalah tidak dapat ditentukannya langkah-langkah yang tepat untuk melakukan penghematan dan efisiensi dari segi peralatan dan fasilitas pemesinan. Penelitian ini bertujuan untuk menganalisa kinerja motor induksi saat perubahan katub (valve) pompa air diubah, terhadap arus stator, arus rotor, putaran, torka dan efisiensi motor induksi tiga phasa di kantor Walikota Pekanbaru Riau.

\section{Daya Motor induksi}

Aliran daya pada motor induksi dapat dikatakan sebagai transformator yang berputar. Pada transformator keluaran pada lilitan sekundernya adalah daya listrik, sedangkan pada motor induksi keluaran lilitan sekundernya (rotor) daya mekanik seperti pada Gambar 1 [1]

Daya input motor induksi [2]:

$$
P_{i n}=\sqrt{3} \times V_{t} \times I \times \cos \varphi
$$

Rugi-rugi tembaga stator [2] :

$$
P_{s c l}=3 \times I_{1}^{2} \times R_{1}
$$

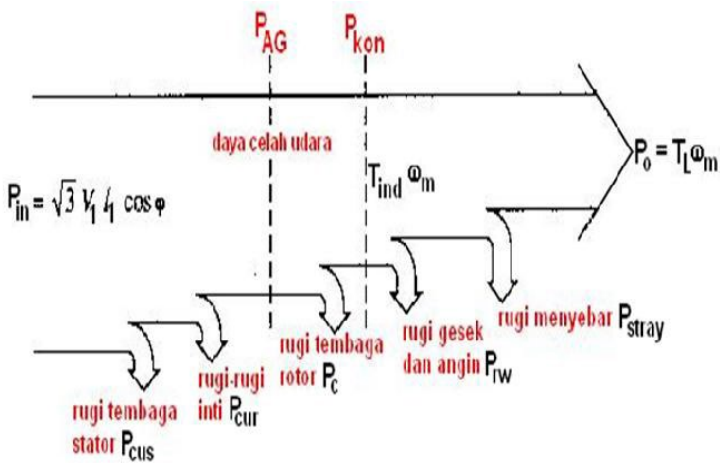

Gambar 1. Diagram Aliran Daya Motor Induksi

Rugi-rugi inti stator [2] :

$$
P_{\text {core }}=\frac{3 \times E_{1}^{2}}{R_{c}}
$$

Daya yang dikirim pada celah udara [2]:

$$
P_{a g}=P_{i n}-P_{s c l}
$$

Rugi-rugi tembaga rotor [2]:

$$
P_{r c l}=s \times P_{a g}
$$

Daya yang dikonversikan elektrik ke mekanis [2]:

$$
P_{\text {convertion }}=(1-s) \times P_{a g}
$$

Daya output [2] :

$$
P_{\text {out }}=P_{\text {convertion }}-P_{r c l}
$$

Kecepatan sudut pada stator $\left(\omega_{\mathrm{s}}\right)$ motor induksi dapat diketahui menggunakan persamaan sebagai berikut [2] :

$$
\omega_{s}=\frac{n_{s}}{60} \times 2 \pi
$$

Sedangkan untuk kecepatan sudut pada rotor diketahui menggunakan persamaan sebagai berikut [2] : 
SainETIn (Jurnal Sain, Energi, Teknologi \& Industri), Vol. 4 No. 2, Juni 2020, pp. 57 - 64

ISSN 2548-6888 print, ISSN 2548-9445 online

$$
\omega_{r}=\frac{n_{r}}{60} \times 2 \pi
$$

Untuk mengetahui torka induksi dapat diketahui menggunakan persamaan sebagai berikut [2] :

$$
\tau_{\text {ind }}=\frac{P_{a g}}{\omega_{s}}
$$

Untuk menghitung torka output dapat diketahui dengan menggunakan persamaan sebagi berikut $[2]:$

$$
\tau_{\text {load }}=\frac{P_{\text {out }}}{\omega_{r}}
$$

\section{Rangkaian Ekivalen Motor Induksi}

Kerja motor induksi sama seperti kerja transformator berdasarkan prinsip induksielektromagnet. Oleh karena itu motor induksi dapat dianggap sebagai transformator dengan rangkaian sekunder yang berputar seperti pada Gambar 2.

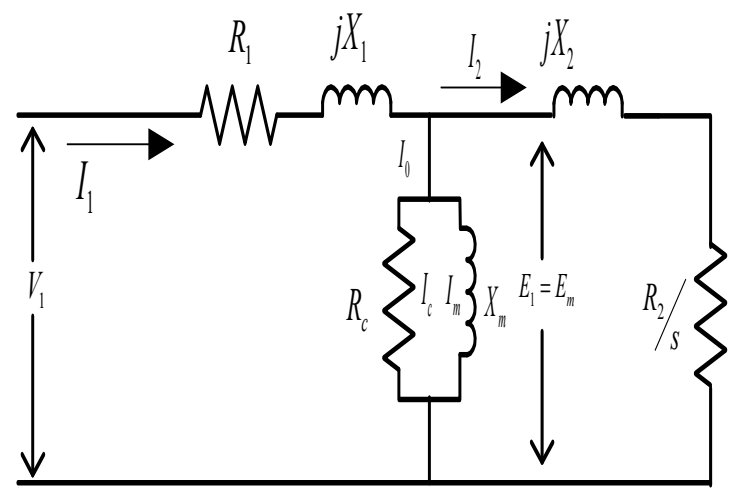

Gambar 2. Rangkaian Ekivalen Motor Induksi

Untuk menghitung arus rotor dapat dihitung dengan menggunakan persamaan sebagai berikut [2] :

$$
I_{2}=\frac{E_{2}}{\sqrt{R_{2}^{2}+X_{2}^{2}}}=\frac{V_{1}}{Z_{S}}
$$

Untuk menghitung Impedansi total dapat dihitung dengan menggunakan persamaan sebagai berikut [3] :

$$
Z_{\text {total }}=\left(R_{1}+j X_{1}\right)+\left(Z_{p}\right)
$$

Untuk menghitung Impedansi ekivalen seri dapat dihitung dengan menggunakan persamaan sebagai berikut [3] :

$$
Z_{S}=R_{1}+\frac{R_{2}}{S}+j\left(X_{1}+X_{2}\right)
$$

Untuk menghitung arus stator dapat dihitung dengan menggunakan persamaan sebagai berikut [4] :

$$
I_{1}=\frac{V_{1}}{Z_{t}}
$$

Debit aliran (rate of discharge) sesuai dengan hukum kontinuitas, maka debit aliran (kecepatan aliran didalam pipa) dapat dicari dengan persamaan [4] :

$$
V=\frac{4 \times Q}{\pi \times D i^{2}}
$$

\section{Pompa Sentrifugal}

Pompa adalah suatu alat yang digunakan untuk memindahkan suatu cairan dari suatu tempat ke tempat lain dengan cara menaikan tekanan cairan tersebut. Kenaikan tekanan cairan tersebut digunakan untuk mengatasi hambatanhambatan pengaliran. Hambatan-hambatan pengaliran itu dapat berupa perbedaan tekanan perbedaan ketinggian atau hambatan gesek. Pompa sentrifugal memanfaatkan energi kinetic dari fluida untuk dirubah menjadi energi kecepatan dan tekanan. Putaran impeller akan menghasilkan gaya sentrifugal dan melempar fluida ke sisi luar sehingga kecepatan meningkat.Kecepatan tersebut kemudian diarahkan oleh cassing pompa (volute atau difuser) menjadi tekanan, keluar melalui discharge.

Pompa ini harus dijamin ketersediaan fluida dengan energi tertentu pada saluran isapnya. Beban pompa sentrifugal dipengaruhi dalam bentuk persyaratan torka beban pada poros motor. Beban torka ini tergantung pada persyaratan proses head, laju aliran, dan kecepatan operasi motor, dengan kondisi beban yang berubah, motor pompa sentrifugal menyala, dimodelkan sebagai torka beban. 
SainETIn (Jurnal Sain, Energi, Teknologi \& Industri), Vol. 4 No. 2, Juni 2020, pp. 57 - 64

ISSN 2548-6888 print, ISSN 2548-9445 online

Karena itu menjadi penting untuk mempertimbangkan perubahan beban torka di bawah variasi tegangan dan ketidakseimbangan seperti pada Gambar 3 [6], [7].

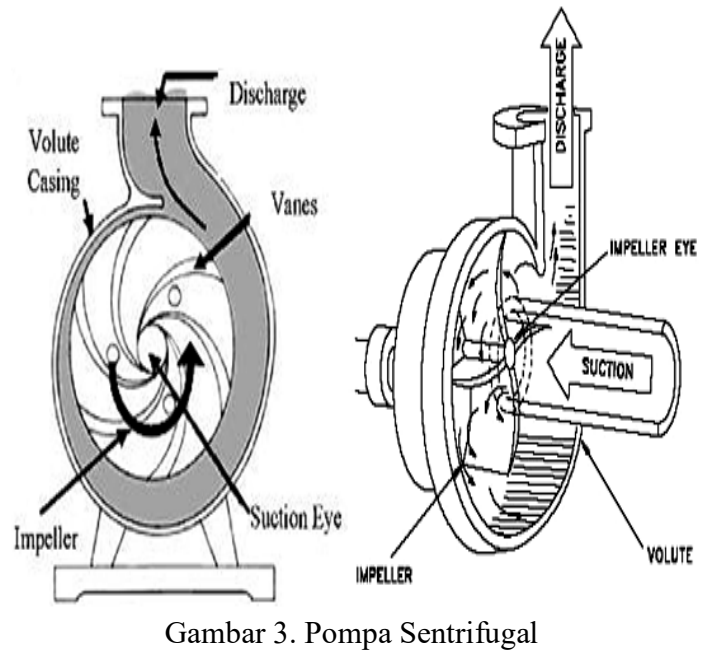

Untuk mengetahui head total keseluruhan sepanjang instalasi perairan dapat dihitung menggunakan persamaan [6] :

$$
h_{t i}=h_{i}+h_{f_{\text {elbow } 90^{\circ}}}+h_{f_{\text {tee }}}
$$

Dimana :

$$
\begin{aligned}
\mathrm{h}_{\mathrm{s}}= & \text { head statis total }(\mathrm{m}) \\
\Delta \mathrm{hp}= & \text { Perbandingan head tekanan (m) } \\
\mathrm{hf}= & \text { Kerugian head dipipa, katub, } \\
& \text { belokan, sambungan }
\end{aligned}
$$

Sementara untuk menghitung putaran synchronous pada motor induksi tiga phasa dapat dihitung dengan menggunakan persamaan sebagai berikut [8] :

$$
n_{s}=\frac{120 \times f_{s}}{p}
$$

Banyak penelitian telah melakukan dalam mengatur kecepatan putaran motor induksi. Baik dengan menggunakan Variable Speed Drive (VSD) [9]-[13], maupun Programmable Logic Controller (PLC) [14]. Pengaturan ini dapat digunakan untuk menyesuaikan kecepatan putaran ataupun dalam rangka menghemat energi yang digunakan.

\section{METODE PENELITIAN}

Kantor Walikota Pekanbaru sekarang berada di jl. Badak Kecamatan Tenayan Raya, kantor Walikota ini baru beroperasi 25 Maret 2019 yang memiliki gedung 8 lantai, untuk memenuhi kebutuhan air bersih di gedung bertingkat 8 ini pihak dari kantor Walikota memanfaatkan motor listrik untuk memenuhi ketersediaan air bersih yang memadai. Motor listrik merupakan mesin listrik yang merubah energi listrik menjadi energi gerak pemanfaatan energi gerak ini yang kemudian banyak digunakan oleh beberapa gedung bertingkat untuk mempermudah proses pendistribusian air. Sistem pendistribusian air bersih di kantor Walikota Pekanbaru seperti pada Gambar 4.

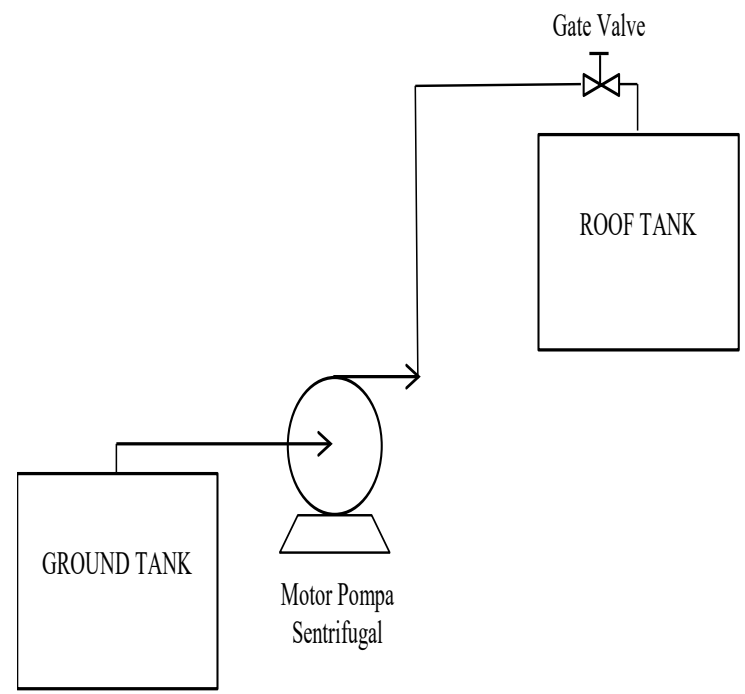

Gambar 4. Sistem Pendistribusian Air Bersih Di Kantor Walikota Pekanbaru

Pada Gambar 4 memperlihatkan sistem pendistribusian air pada kantor Walikota Pekanbaru. Saat pompa celup yang berada di dalam sumur bor di hidupkan maka air yang di hisap oleh pompa celup akan menuju ke penampungan ground tank yang terletak tidak jauh dari pompa celup, setelah pompa celup mengisi air penuh di ground tank lalu selanjut nya air akan di transferkan menuju ke penampungan roof tank dengan menggunakan motor pompa tiga phasa, setelah itu air yang sudah di tampung di roof tank selanjutnya akan di-transfer menggunakan motor pompa untuk sampai ke toilet-toilet kantor tersebut. 
SainETIn (Jurnal Sain, Energi, Teknologi \& Industri), Vol. 4 No. 2, Juni 2020, pp. 57 - 64

ISSN 2548-6888 print, ISSN 2548-9445 online

\section{Alur Penelitian}

Selanjutnya diagram alir (Flow Chart) penelitian seperti adalah sebagaimana terlihat pada Gambar 5.

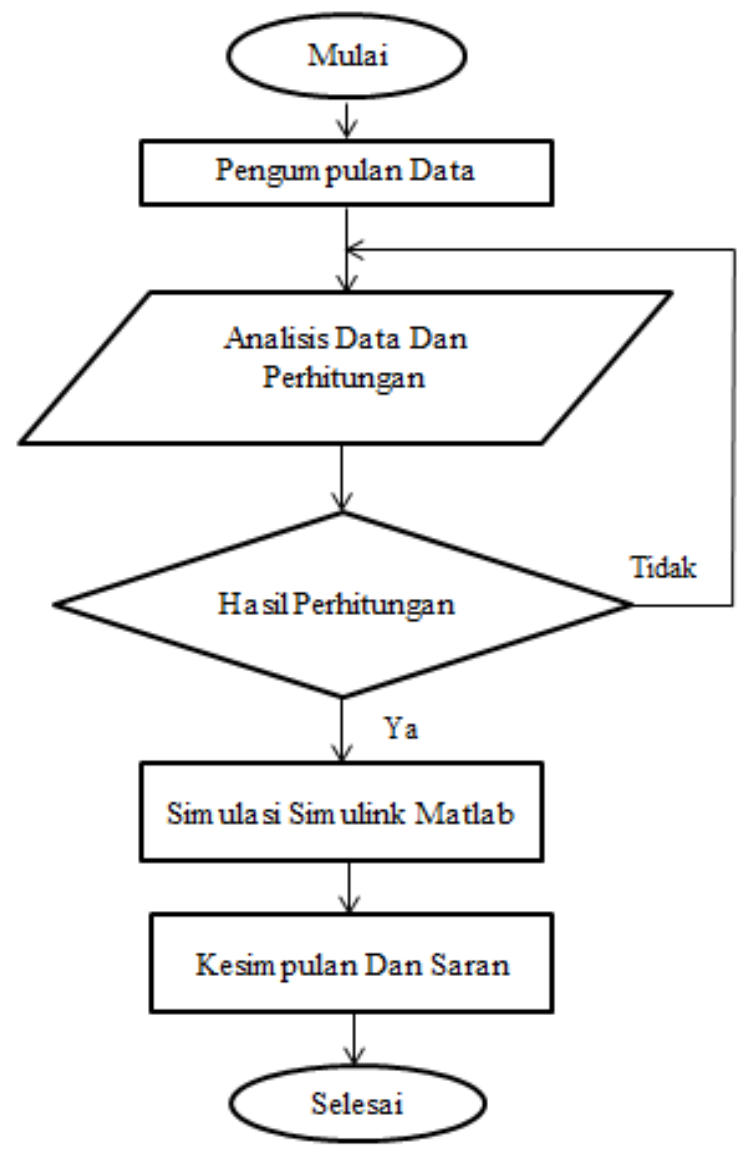

Gambar 5. Diagram Alur (Flow Chart) Penelitian

\section{HASIL DAN PEMBAHASAN}

Hasil data yang diperoleh dari pengukuran secara langsung dan data-data parmeter motor induksi tiga phasa dilapangan maka, dapat menghitung besaran arus stator, arus rotor, torka, putaran dan efisiensi pada motor induksi tiga phasa sebagai penggerak pompa air saat bukaan Valve minimal 320 liter/menit, medium 560 liter/menit, maksimal 680 liter/menit :

1) Kecepatan putaran synchronous pada motor induksi tiga phasa seperti persamaan (18) :

$$
n_{s}=\frac{120 \times f_{s}}{p}=\frac{120 \times 50}{2}=3000 \mathrm{rpm}
$$

2) Kecepatan sudut putaran synchronous motor induksi tiga phasa seperti persamaan (8) :

$$
\begin{aligned}
\omega_{s} & =\frac{n_{s}}{60} \times 2 \pi=\frac{3000}{60} \times 2 \pi \\
& =314,159 \mathrm{rad} / \mathrm{s}
\end{aligned}
$$

3) Menghitung kecepatan sudut putaran rotor motor induksi tiga phasa seperti persamaan (9) :

$$
\begin{aligned}
\omega_{r} & =\frac{n_{r}}{60} \times 2 \pi=\frac{2979}{60} \times 2 \pi \\
& =311,960 \mathrm{rad} / \mathrm{s}
\end{aligned}
$$

4) Arus pada lilitan stator motor induksi tiga phasa seperti persamaan (15) :

$$
\begin{aligned}
I_{1} & =\frac{V_{1}}{Z_{t}} \\
& =\frac{229,785 \angle 0^{\circ}}{36,970 \angle 52,727^{\circ}} \\
& =6,215 \angle-52,727^{\circ} \text { Amper }
\end{aligned}
$$

5) Menghitung besaran arus pada rotor motor induksi tiga phasa seperti persamaan (12) :

$$
\begin{aligned}
I_{2} & =\frac{V_{1}}{Z_{s}} \\
& =\frac{229,785 \angle 0^{\circ}}{54,971 \angle 3,890^{\circ}} \\
& =4,180 \angle-3,890^{\circ} \text { Amper }
\end{aligned}
$$

6) Torka induksi yang dihasilkan motor induksi tiga phasa saat bukaan valve minimal seperti persamaan (10) :

$$
\tau_{\text {ind }}=\frac{P_{a g}}{\omega_{s}}=\frac{2527,108}{314,159}=8,044 \text { N.m }
$$

7) Sementara torka beban yang dipikul motor induksi tiga phasa seperti persamaan (11):

$$
\tau_{\text {load }}=\frac{P_{\text {out }}}{\omega_{r}}=\frac{2491,72}{311,960}=7,987 \text { N.m }
$$

8) Data yang diperoleh dapat menghitung kecepatan aliran air pada pompa motor induksi tiga phasa seperti persamaan (16) :

$$
V=\frac{4 \times Q}{\pi \times D i^{2}}
$$


SainETIn (Jurnal Sain, Energi, Teknologi \& Industri), Vol. 4 No. 2, Juni 2020, pp. 57 - 64

ISSN 2548-6888 print, ISSN 2548-9445 online

$$
\begin{aligned}
& =\frac{4 \times 5,33 \times 10^{-3}}{3,14 \times(0,073)^{2}}=\frac{0,021}{0,0167} \\
& =1,257 \mathrm{~m} / \mathrm{s}
\end{aligned}
$$

9) Head total pada pipa dorong (tekan) seperti persamaan (17) :

$$
\begin{aligned}
h_{t i} & =h_{i}+h_{f_{\text {elbow } 90^{\circ}}}+h_{f_{\text {tee }}} \\
& =0,0032+0,043+0,007 \\
& =0,0539 m
\end{aligned}
$$

Dari hasil analisa motor induksi tiga phasa sebagai pompa air dan kecepatan aliran air beserta head total yang terdapat pada kantor Walikota Pekanbaru Riau pada saat bukaan valve minimal 320 liter/menit, medium 560

\begin{tabular}{|c|c|c|c|c|}
\hline \multirow[b]{2}{*}{ No } & \multirow[b]{2}{*}{ Analisa } & \multicolumn{3}{|c|}{ Pengaturan Bukaan Valve } \\
\hline & & $\begin{array}{l}\text { Minimal } \\
\text { (320 liter/ } \\
\text { menit) }\end{array}$ & $\begin{array}{c}\text { Medium } \\
\text { (560 liter/ } \\
\text { menit) }\end{array}$ & $\begin{array}{c}\text { Maksimal } \\
\text { (680 liter/ } \\
\text { menit) }\end{array}$ \\
\hline 1 & $\begin{array}{l}\text { Daya } \\
\text { Masuk } \\
\text { (Watt) }\end{array}$ & 2592,031 & 4597,477 & 5848,312 \\
\hline 2 & $\begin{array}{c}\text { Arus } \\
\text { Stator } \\
\text { (Amper) } \\
\text { Arus }\end{array}$ & 6,215 & 8,389 & 10,006 \\
\hline 3 & $\begin{array}{l}\text { Rotor } \\
\text { (Amper) }\end{array}$ & 4,180 & 7,236 & 9,319 \\
\hline 4 & $\begin{array}{l}\text { Putaran } \\
\text { Rotor } \\
\text { (rpm) }\end{array}$ & 2979 & 2963 & 2950 \\
\hline 5 & Slip (\%) & 0,7 & 1,2 & 1,6 \\
\hline 6 & $\begin{array}{c}\text { Torka } \\
\text { Induksi } \\
\text { (N.m) } \\
\text { Torka }\end{array}$ & 8,044 & 14,257 & 18,080 \\
\hline 7 & $\begin{array}{l}\text { Beban } \\
\text { (N.m) }\end{array}$ & 7,987 & 14,080 & 17,798 \\
\hline 8 & $\operatorname{Cos} \varphi$ & 0,605 & 0,797 & 0,85 \\
\hline 9 & $\begin{array}{c}\text { Kecepat } \\
\text { an } \\
\text { Aliran } \\
(\mathrm{m} / \mathrm{s})\end{array}$ & 1,257 & 2,215 & 2,714 \\
\hline 10 & $\begin{array}{c}\mathrm{h}_{\mathrm{i} \text { saluran }} \\
(\mathrm{m})\end{array}$ & 0,0032 & 0,0088 & 0,012 \\
\hline
\end{tabular}
liter/menit, maksimal 680 liter/menit seperti

\begin{tabular}{|c|c|c|c|c|}
\hline 11 & $\begin{array}{c}\mathrm{h}_{\mathrm{f} \text { elbow }} \\
90^{\circ}(\mathrm{m})\end{array}$ & 0,043 & 0,129 & 0,194 \\
\hline & $\mathrm{h}_{\mathrm{f} \text { tee }(\mathrm{m})}$ & 0,007 & 0,021 & 0,031 \\
\hline & $\begin{array}{l}\text { Head } \\
\text { Total } \\
(\mathrm{m})\end{array}$ & 0,0539 & 0,158 & 0,236 \\
\hline
\end{tabular}
Tabel 1.

Tabel 1. Hasil Perhitungan Motor Induksi Tiga Phasa Dan Kecepatan Aliran Air
Hasil perhitungan motor induksi tiga phasa pada arus stator, arus rotor, dan daya masuk terhadap bukaan valve dapat digambarkan dengan grafik seperti Gambar 6.

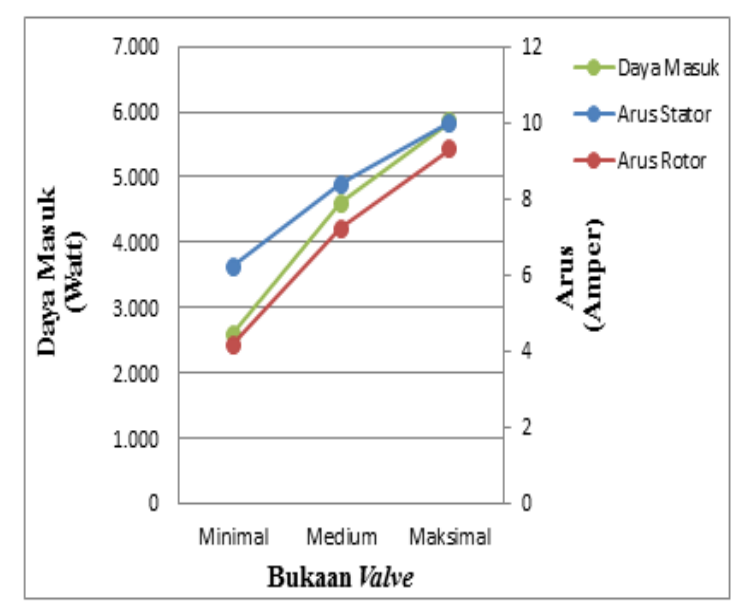

Gambar 6. Grafik Arus Stator, Arus Rotor dan Daya Masuk

Analisa perhitungan motor induksi tiga phasa pada slip, torka induksi dan putaran rotor yang ditunjukan pada Tabel 1. Digambarkan dengan grafik seperti Gambar 7.

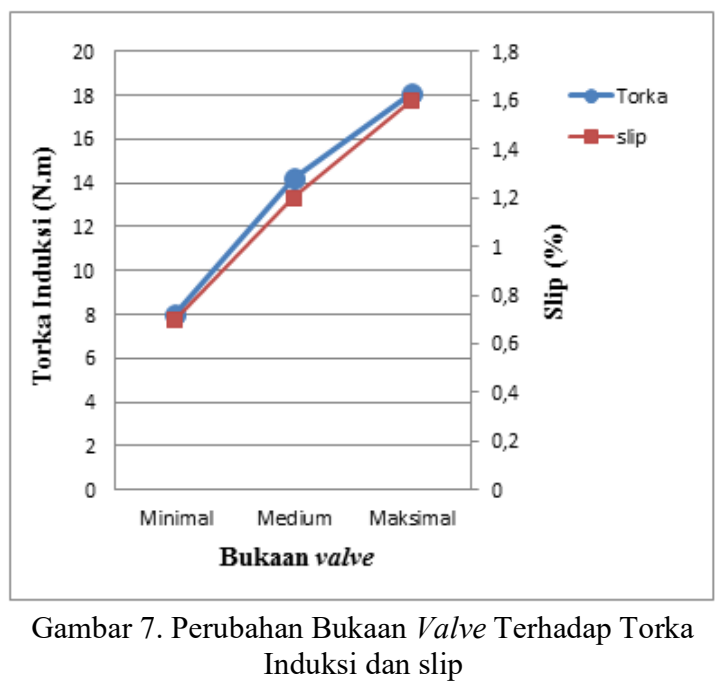

Simulasi motor induksi tiga phasa pada kantor Walikota Pekanbaru Riau saat bukaan 
SainETIn (Jurnal Sain, Energi, Teknologi \& Industri), Vol. 4 No. 2, Juni 2020, pp. 57 - 64 ISSN 2548-6888 print, ISSN 2548-9445 online

valve minimal, medium, maksimal. Untuk mengetahui gelombang yang dihasilkan pada arus stator,arus rotor, torka dan putaran pada saat bukaan valve minimal, medium, maksimal maka dilakukan simulasi dengan Simulink Matlab seperti pada Gambar 8 .

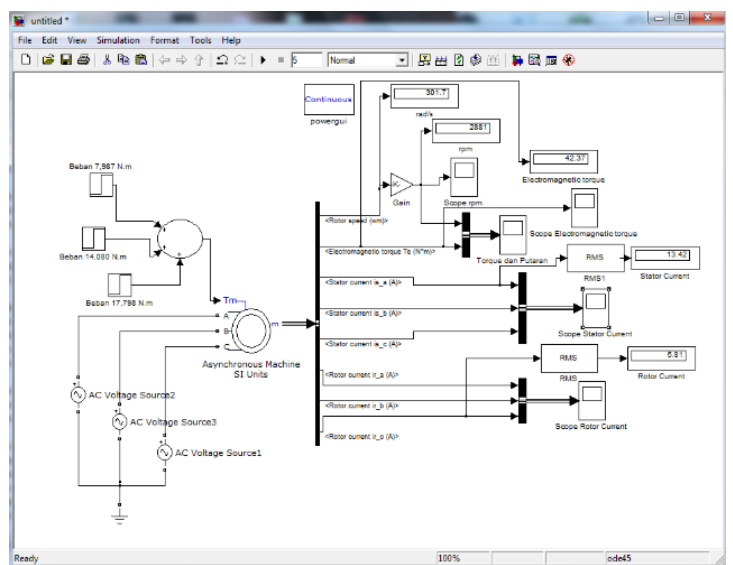

Gambar 8. Simulasi Motor Induksi Tiga Phasa Saat Torka Beban Minimal 7,987 N.m, Medium 14,080 N.m, Maksimal 17,798 N.m

Gelombang arus stator yang dihasilkan seperti pada Gambar 9.

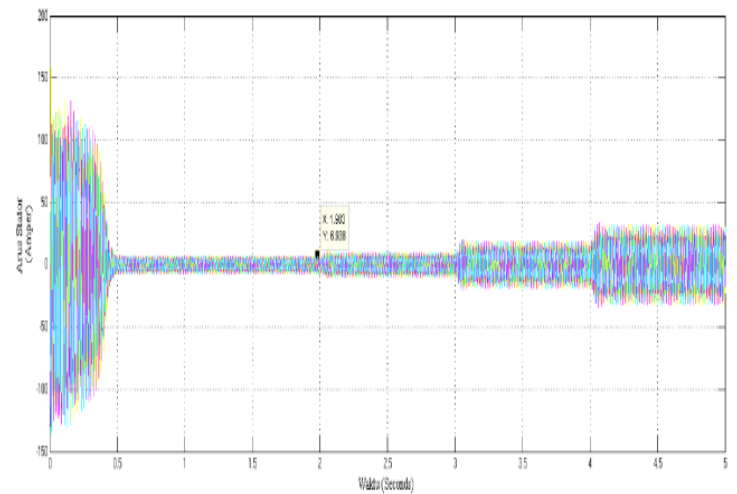

Gambar 9. Gelombang Arus Stator

Gelombang Arus rotor yang dihasilkan seperti pada Gambar 10.

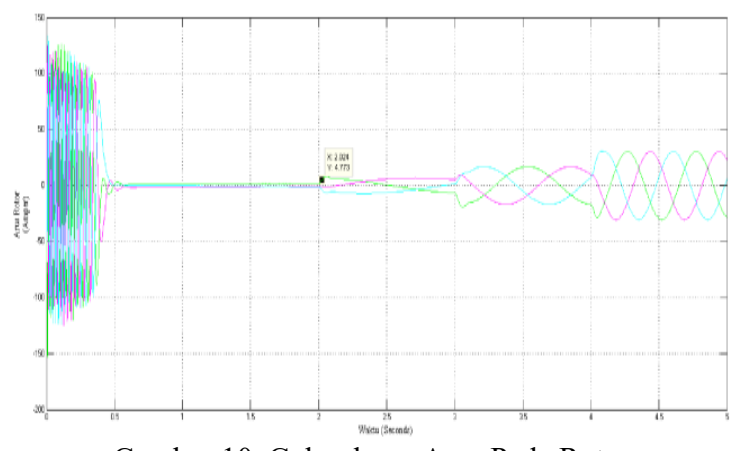

Gambar 10. Gelombang Arus Pada Rotor

Gelombang Electromagnetic Torque yang dihasilkan seperti pada Gambar 11.

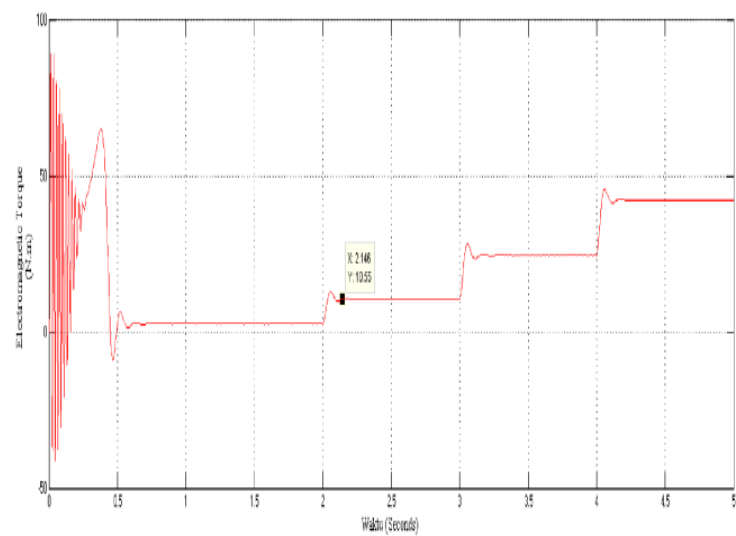

Gambar 11. Gelombang Electromagnetic Torque

Gelombang putaran rotor yang dihasilkan seperti pada Gambar 12.

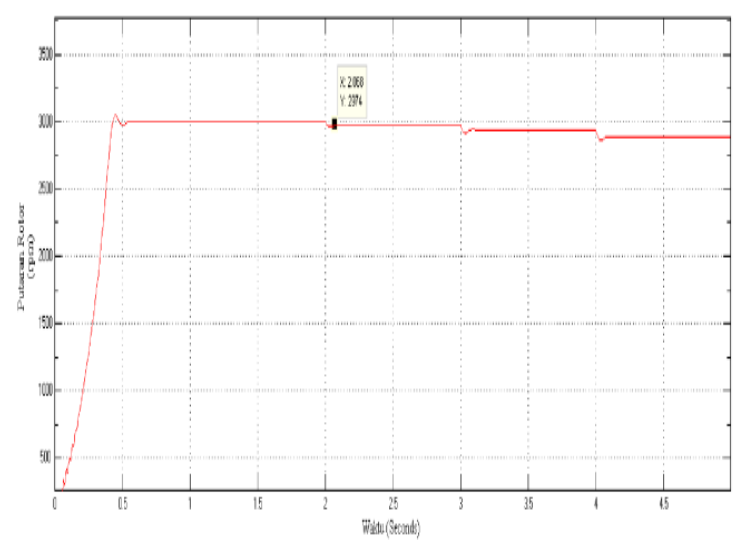

Gambar 12. Putaran Rotor Motor Induksi Tiga Phasa

\section{KESIMPULAN}

Berdasarkan hasil penelitian motor induksi tiga phasa yang terdapat di kantor Walikota, maka dapat disimpulkan sebagai berikut :

1. Hasil perhitungan motor induksi tiga phasa pada bukaan valve minimum 320 liter/menit, arus stator 6,215 Amper dan arus rotor 4,180 Amper, pada bukaan valve medium 560 liter/menit arus stator 8,389 Amper dan arus rotor 7,236 Amper, pada bukaan valve maksimum 680 liter/menit arus stator 10,006 Amper dan arus rotor 9,319 Amper.

2. Pada saat bukaan valve minimal 320 liter/menit didapat putaran rotor sebesar 2979 rpm, saat bukaan valve medium 560 liter/menit didapat putaran rotor sebesar 2963 
rpm, saat bukaan valve maksimal 680 liter/menit didapat putaran rotor sebesar sebesar $2950 \mathrm{rpm}$.

3. Torka induksi yang dihasilkan motor induksi tiga phasa pada saat bukaan valve minimal 320 liter/menit sebesar 8,044 N.m, saat bukaan valve medium 560 liter/menit sebesar 14,257 N.m, saat bukaan valve maksimal 680 liter/menit sebesar 18,080 N.m. Sedangkan torka beban saat bukaan valve minimal 320 liter/menit sebesar 7,987 N.m, saat bukaan valve medium 560 liter/menit sebesar 14,080 N.m, saat bukaan valve minimal 680 liter/menit sebesar 17,798 N.m.

4. Perhitungan motor induksi tiga phasa pada saat bukaan valve minimal 320 liter/menit diperoleh efisiensi motor sebesar 96,1\%, pada saat bukaan valve medium 560 liter/menit efisiensi motor sebesar 95,1 \%, pada saat bukaan valve maksimal 680 liter/menit, efisiensi motor sebesar $94,0 \%$.

\section{DAFTAR PUSTAKA}

[1] J. H. Manurung and E. Warman, "Analis Slip Optimal Motor Induksi Tiga Fasa untuk Efisiensi Optimal pada Beban Rendah," Singuda Ensikom, vol. 3, no. 3, pp. 100-105, 2013.

[2] S. J. Chapman, Electric Machinery Fundamentals, 5th ed. New York: McGraw-Hill, 2012.

[3] T. Gonen, Electrical Machines with Matlab, 2nd ed. London: Tailor and Francis Group, 2012.

[4] B. S. Guru, Electric Machinery and Transformers, 3rd ed. New York: Oxford University Press, Inc, 2001.

[5] I. Mustafid, Halomoan, "Menentukan Nilai Koefisien Gesek Pada Pipa Dengan Menggunakan Aplikasi Microsoft Visual Basic," Universitas Gunadarma, 2005.

[6] Y. Yuliani, "Analisa Perbandingan Kinerja Pompa Sentrifugal dengan Pengaturan Bukaan Katup,” J. Sainstek, vol. 5, no. 2, pp. 90-97, 2017.

[7] P. Karan, V. Himanshu, and P. Amit, "A Review on Improvement of Efficiency of Centrifugal Pump by Altering Design Parameters," Int. Conf. Curr. Res. Trends Eng. Technol., vol. 4, no. 5, pp. 606-611, 2018.

[8] Zuhal, "Dasar Tenaga Listrik Dan Elektonika Daya." p. 264, 1988.

[9] A. Atmam, A. Tanjung, and Z. Zulfahri, "Analisis Penggunaan Energi Listrik Motor Induksi Tiga Phasa Menggunakan Variable Speed Drive (VSD)," SainETIn, vol. 2, no. 2, pp. 52-59, 2018.

[10] Erisman, H. Eteruddin, and A. Atmam, "Evaluasi Kinerja Motor Ship Moving 3 Phasa Menggunakan Variable Speed Drive (VSD) Pada PLTU Tenayan Raya Pekanbaru," in Seminar Nasional Cendekiawan ke 4, 2018, pp. 237-242.

[11] R. A. Rangkuti, A. Atmam, and E. Zondra, "Studi Pengaturan Kecepatan Motor Induksi Tiga Phasa Menggunakan Variable Speed Drive (VSD) Berbasis Programmable Logic Controller (PLC)," Jurnal Teknik, vol. 14, no. 1, pp. 121128, 2020.

[12] E. P. Wibowo, E. Zondra, and U. Situmeang, "Studi Penggunaan Variable Speed Drive Untuk Pengaturan Kecepatan Motor Exhaust Fan Pada Dyno Test Room PT. Trakindo Utama Pekanbaru," Jurnal Teknik, vol. 12, no. 2, pp. 85-96, 2018.

[13] C. R. Aritonang, A. Atmam, and E. Zondra, "Analisis Putaran Motor Pada Electrical Submersible Pump (ESP) Menggunakan Fuzzy Logic Controler Berbasis Python," SainETIn, vol. 4, no. 1, pp. 32-39, 2019.

[14] S. Nuari, A. Atmam, and E. Zondra, "Analisis Starting Motor Induksi Tiga Phasa Menggunakan Programmable Logic Controller (PLC)," SainETIn, vol. 2, no. 2, pp. 60-67, 2018. 